\title{
Investigation of Correlation between Neurological Diseases and Breath Hexanal
}

\section{H Akman ${ }^{1 *}$, I Bayrakli ${ }^{2}$ and S Kutluhan ${ }^{3}$}

${ }^{1}$ Department of Biomedical Engineering, Suleyman Demirel University, Turkey

${ }^{2}$ Department of Electrical and Electronical Engineering, Aksaray University, Turkey

${ }^{3}$ Department of Neurology, Suleyman Demirel University, Turkey

\begin{abstract}
Breath analysis is a method that has the potential to be used as a non-invasive method for the diagnosis of diseases, in the planning of drug use, and in indicating the health status of the patient, and of which importance increases with each passing day. The aim of this study is to examine neurological diseases from breath hexanal. In our study, the breaths of a total of 29 individuals consisting of 9 multiple sclerosis patients, 8 Parkinson's patients and 12 healthy individuals in the control group were examined by means of the thermal desorption gas chromatography mass spectroscopy method. According to the results obtained, hexanal molecule, known as the biomarker for lipid peroxidation, was observed in patients with a statistically significant difference compared to the control group with multiple sclerosis patients as $p=0.048$. No correlation was found between Parkinson's patient and the control group.
\end{abstract}

Keywords: Breath analysis; Multiple sclerosis; Parkinson's disease; Hexanal

\section{Introduction}

The breath analysis method has the potential to be used in the diagnosis of diseases, in the follow-up of treatment processes, and in the investigation of metabolisms. The diagnosis of diseases by the breath analysis will provide a great convenience for both patients and doctors. For example, the diagnosis and treatment process of MS disease can be painful and disturbing for patients. During the initial diagnosis of MS disease, cerebrospinal fluid (CSF) is taken with a needle having a depth of approximately $8-10 \mathrm{~cm}$. It is known that in patients with MS, CSF contains immunoglobulins synthesised in the central nervous system. In the event that the disease is diagnosed by breath, a risk-free, painless and an easy method will be provided for patients and doctors. The main mechanisms that play a role in the formation of neurodegenerative diseases are oxidative stress, mitochondrial dysfunction and inflammation [1]. The brain is very sensitive to oxidative damage due to the high amount of polyunsaturated fatty acid, high-speed metabolic activity and low antioxidant defence capacity [2].

There is not much study about breath analysis of MS and Parkinson's diseases. In a study in which lipid peroxidation is predicted to increase with the damage of the myelin sheath consisting of the lipid structure at the time of the attack [3], ethane and pentane molecules which are the biomarkers of lipid peroxidation were examined from breath. At the time of the MS attack, it was determined that the breath pentane levels become to be higher, but the ethane molecule levels don't increase. It was interpreted that the reason underlying the nonincrease of ethane molecule levels may be due to the low unsaturated fat concentration in the brains of MS patients. It was emphasized that the pentane molecule levels increased in direct proportion to the increased oxidative stress. Tisch et al. studied breath air of Alzheimer's patients and Parkinson's patients to distinguish these diseases from breath and showed remarkable results accuracy of 85,78 and $84 \%$, respectively [4]. In another study, the levels of hexanal molecules in the breath of MS patients were found higher than the control group and it was indicated that the hexanal molecule could be used with $80.4 \%$ accuracy in the diagnosis of MS disease [5]. According to our study hexanal molecule is higher in MS patients like Ionescu et al. The concentrations of the breath molecules of the healthy individuals in the literature are shown in the Table 1.

The present study has been done for better understanding the

\begin{tabular}{|c|c|}
\hline \multicolumn{2}{|c|}{ MS Patients } \\
\hline $\begin{array}{c}\text { Gender } \\
\text { (male/female) }\end{array}$ & $3 / 6$ \\
\hline \multirow{3}{*}{ Age (years) } & Between 13 and 49 years \\
\hline & Average: 32,9 years \\
\hline & Standard Deviation (SD): 9,7 \\
\hline \multirow{3}{*}{$\mathrm{BMI}\left(\mathrm{kg} \mathrm{m}^{-2}\right)$} & Between 16,5 and 37,5 \\
\hline & Average $: 24,3$ \\
\hline & SD: 5,6 \\
\hline \multicolumn{2}{|c|}{ Parkinson's Patients } \\
\hline $\begin{array}{c}\text { Gender } \\
\text { (male/female) }\end{array}$ & $6 / 2$ \\
\hline \multirow{3}{*}{ Age (years) } & Between 40 and 72 years \\
\hline & Average: 54,1 years \\
\hline & Standard Deviation (SD): 12,2 \\
\hline \multirow{3}{*}{$\mathrm{BMI}\left(\mathrm{kg} \mathrm{m}^{-2}\right)$} & Between 19,3 and 33 \\
\hline & Average: 23,6 \\
\hline & SD: 4,4 \\
\hline \multicolumn{2}{|c|}{ Healthy Control Group } \\
\hline $\begin{array}{c}\text { Gender } \\
\text { (male/female) }\end{array}$ & $10 / 2$ \\
\hline \multirow{3}{*}{ Age (years) } & Between 22 and 42 years \\
\hline & Average: 27,8 years \\
\hline & Standard Deviation (SD): 7,3 \\
\hline \multirow{3}{*}{ BMI $\left(\mathrm{kg} \mathrm{m}^{-2}\right)$} & Between 21 and 26,4 \\
\hline & Average : 24,2 \\
\hline & SD: 1,5 \\
\hline
\end{tabular}

Table 1: Demographic, clinical and laboratory features of 13 MS patients, 8 Parkinson's patients, and 12 healthy volunteers.

${ }^{*}$ Corresponding author: Dr. Hatice Akman, Department of Biomedical Engineering, Suleyman Demirel University, Turkey, Tel: 2462111848; E-mail: haticeakman@sdu.edu.tr

Received December 04, 2017; Accepted April 10, 2018; Published April 18, 2018

Citation: Akman H, Bayrakl I, Kutluhan S (2018) Investigation of Correlation between Neurological Diseases and Breath Hexanal. J Bioanal Biomed 10: 56-59. doi:10.4172/1948-593X.1000205

Copyright: $\odot 2018 \mathrm{Akman} \mathrm{H}$, et al. This is an open-access article distributed under the terms of the Creative Commons Attribution License, which permits unrestricted use, distribution, and reproduction in any medium, provided the original author and source are credited. 
metabolism of the diseases under investigation and for convenient and non-invasive diagnosis of the diseases in question. In our study, hexanal molecules present in the breath of a total of 29 individuals consisting of 9 multiple sclerosis patients (MS), 8 Parkinson's patients and 12 healthy individuals in the control group were examined by means of the thermal desorption gas chromatography mass spectroscopy (TDGC/MS) method. Statistically significant differences were observed between the hexanal molecule and MS patients and the control group. No correlation was found between the hexanal levels present in the breaths of Parkinson's patients and the control group. MS attacks are currently diagnosed by MR. During the patient's waiting for MR, the attack status can damage the patient. During the MS attacks, the non-invasive analyses of the amounts of hexanal, molecules found in the breath can be a significant study and it can provide an immediate intervention for attacks.

\section{Methods}

The information about the patients and the control group of which breath samples were taken is given in Table 1. Patients with a respiratory disorder such as active upper respiratory tract infection, etc., patients with severe neurological deficits that would prevent the evaluation of the patients, patients with cognitive impairment and coexistent depression and/or another systemic disorder, and patients with an EDSS score of over 6.5 for MS patients were not included in the study. Information on the age, height, weight, medications used, smoking and alcohol consumption of the participants was obtained from the forms filled in. The study was conducted with the patients of Suleyman Demirel Research and Application Hospital and approved by the ethics committee of the hospital. Written consents were obtained from all volunteers regarding their participation in the study.

In our study, the amounts of hexanal in the breaths of MS and Parkinson's patients were examined by being compared with the control group. Statistical calculations were performed by the 'One-Way ANOVA' test using OriginPro 2017 program.

\section{Breath collection}

The exhaled breath samples were collected from each patient and control group before meal (12:00 a.m.). For TD-GC/MS analysis, breath samples were collected by Bio-VOC system, and transferred to TenaxTA 200-mg polymeric thermal desorption tubes (Markes, Bio-VOC). Tenax-TA tubes has low affinity for water, and suitable for trapping of volatile and semi-volatile compounds from breath and vapor. TenaxTA tubes were store at $<4^{\circ} \mathrm{C}$ to minimize the evaporation of VOCs and preserved for about maximum 15 days which is a suitable time to preserve VOCs.

\section{Termal Desorber-Gas Chromatography / Mass Spectroscopy}

GC is commonly used for the breath analysis together with MS. In this study, TD-GC/MS was used for the analysis of related breath molecule levels (Agilent Technologies 7890A 5975C). Volatile organic compounds (VOCs) were thermally desorbed by the thermal desorber injected into GC/MS. The conditions for the thermal desorber are shown in Table 2.

A non-partitioned mode was applied to the TD system. The GC/ MS injector temperature was set at $250^{\circ} \mathrm{C}$ and the flow rate was set at $20 \mathrm{psi}$. The column oven temperature was held at $60^{\circ} \mathrm{C}$ for $4 \mathrm{~min}$ and then raised to $180^{\circ} \mathrm{C}$ by increasing by $20^{\circ} \mathrm{C}$ per min. After being held at $180^{\circ} \mathrm{C}$ for $15 \mathrm{~min}$, the temperature was again raised to $215^{\circ} \mathrm{C}$ at a rate

\begin{tabular}{|c|c|}
\hline \multicolumn{2}{|c|}{$\begin{array}{c}\text { Pre-desorption settings } \\
\text { Split on in standby }\end{array}$} \\
\hline Flow path temperature & $200^{\circ} \mathrm{C}$ \\
\hline Minimum transporter pressure & $5 \mathrm{psi}$ \\
\hline Pre-purification time & $1 \mathrm{~min}$ \\
\hline Tube / sample desorption settings \\
\hline Tube desorption time & $5 \mathrm{~min}$ \\
\hline Tube desorption temperature & $250^{\circ} \mathrm{C}$ \\
\hline Trap Settings & \\
\hline Pre-trap fire purge & Minimum 1 min of trap flow \\
\hline Trap low & $-10^{\circ} \mathrm{C}$ \\
\hline Trap heating rate & Maximum \\
\hline Trap capture / minute & 3 min \\
\hline Split & Open \\
\hline Trap maximum & $300^{\circ} \mathrm{C}$ \\
\hline
\end{tabular}

Table 2: Thermal desorption unit settings

of $4^{\circ} \mathrm{C} / \mathrm{min}$. It was held at this temperature for $20 \mathrm{~min}$. The column oven was also heated up to $240^{\circ} \mathrm{C}$ by $4^{\circ} \mathrm{C}$ per min. It was held at this temperature for $35 \mathrm{~min}$. The analytes were then injected into a capillary column, which was DB-5 non-polar, and of which length was $30 \mathrm{~m}$ and internal diameter was $0.25 \mathrm{~mm}$. The selected ion monitoring (SIM) mode was used to obtain the sub-detection limits. The SIM mode allows us to get much more effective results in the full scan mode. Helium gas (99.999\%) was used as a transporter with a flow of approximately $20 \mathrm{psi}$ in the analytical column. The ionisation of the individual compounds was carried out by electron impact ionisation at $70 \mathrm{eV}$.

For the SIM mode calibration, it is necessary to manually inject and introduce standards at different concentrations to the TD-GC/ MS device. The same temperature program was then applied for the analysis of a sample and the molecules in the breath mixture were identified. Limit of detection (LOD) is found as $0.7 \mathrm{ppb}$. In the study, the calibration curves were observed to be linear.

\section{Results}

The results obtained in our study are given in Figure 1. According to the results below, upon comparing the results of MS and Parkinson's patients and the healthy control group, the levels of molecules examined were lower in the control group when compared to the patients. According to these results, upon comparing the amount of hexanal in the breaths of MS patients and healthy volunteers, it was seen that the hexanal amounts in the breaths of MS patients were significantly higher $(\mathrm{p}=0.048)$.

No correlation of the molecules we examined in MS, Parkinson's patients with age and BMI was found. The results obtained for MS patients are shown in Figure 2 as an example.

\section{Discussion}

\section{Metabolisms related to hexanal molecule}

Lipid peroxidation metabolism: During lipid peroxidation, along with the increase in the formation of reactive oxygen species (ROS) that cause the increase in oxidative stress and neurotoxicity in the brain, an increase in lipid peroxidation markers such as malondialdehyde (MDA) and hexanal, deterioration in mitochondrial functions, and a decrease in antioxidant enzymes such as reduced glutathione (GSH), superoxide dismutase (SOD), glutathione peroxidase (GPx) and glutathione reductase (GRd) are observed [6]. 
The amount of lipid in nerve tissues is especially high. Lipid peroxidation is important in many neurological diseases due to lipidrich membranes of nerve cells. At the first stage of lipid peroxidation, lipid radical is formed by removing an $\mathrm{H}$ atom containing an electron from conjugated double bonds in fatty acids. The lipid radical forms the lipid peroxide radical (LOOH) by reacting with oxygen. $\mathrm{LOOH}$ degradation occurs with the ion catalysis of the transition metals. The cell membrane and organelle lipid peroxidation can be stimulated by free radicals and increases in the presence of transition metals. The formation of the hydroxyl radical $(\mathrm{OH} \cdot)$ from hydrogen peroxide $\left(\mathrm{H}_{2} \mathrm{O}_{2}\right)$ can initiate a chain reaction. As a result of these reactions, aldehydes (e.g. hexanal) emerge as end products. Also 5-HPETE (5-Hydroperoxyeicosatetraenoic acid) is the compound incorporated in the aldehyde structure (Figure 3) $[7,8]$.

The lipid peroxidation metabolism progressing without enzymes is a very harmful chain reaction. In these reactions, the membrane structure is directly damaged and the produced reactive aldehydes indirectly damage other cell components. This can cause many diseases $[9,10]$. Hexanal lipid peroxidation during lipid peroxidation is the molecule that occurs in the breath as a biomarker [11-15].

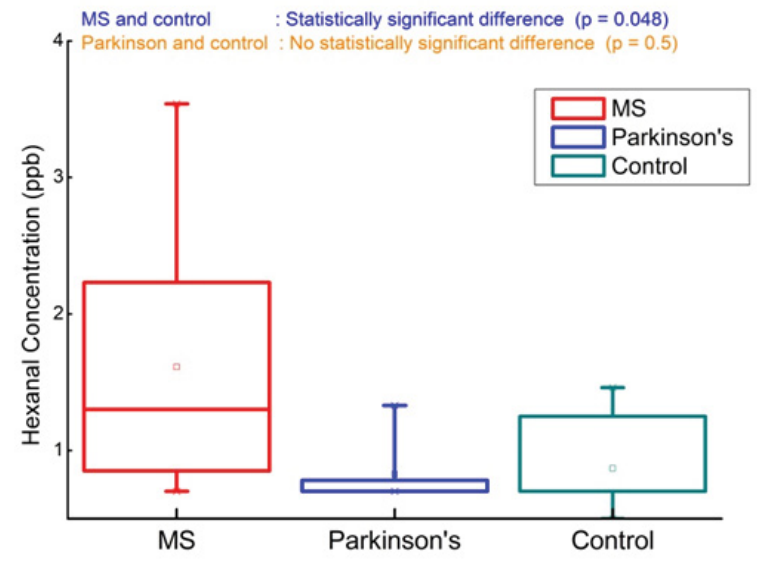

Figure 1: Comparison of the hexanal amount in the breath of, MS and Parkinson's patients and the healthy volunteers with the control group.

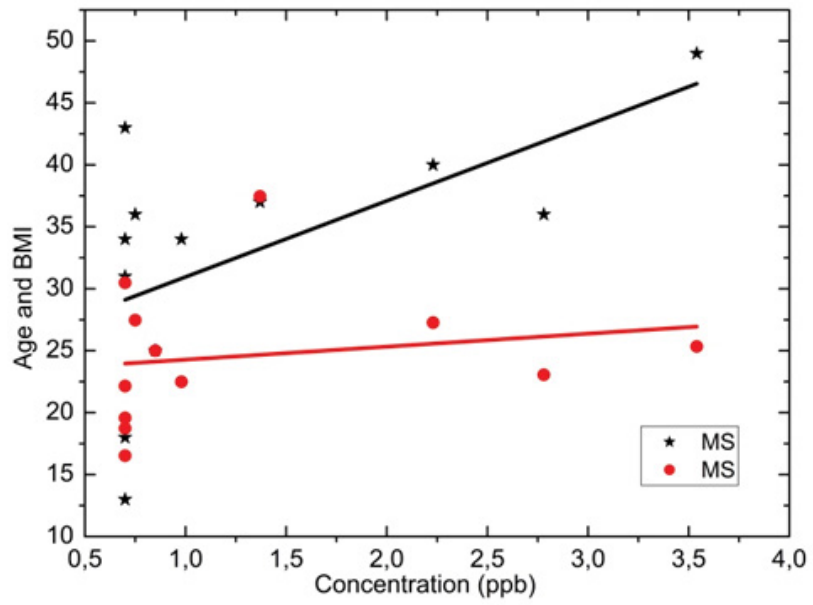

Figure 2: The correlation of hexanal amount in the breaths of MS patients with age and BMI.

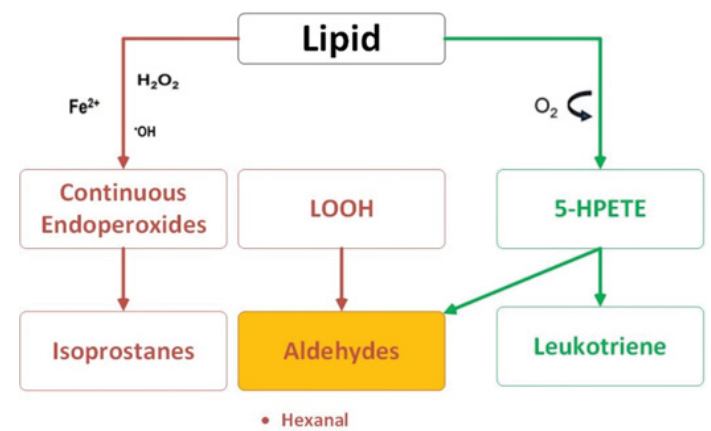

Figure 3: Lipid peroxidation metabolism.

\section{Multiple sclerosis}

In myelinated nerves, nonpolar lipids allow the rapid spread of depolarization waves as electrical isolators. In MS, the theory that the lesion formation develops as these lipids damage the immune system is widespread. Lipids also assist mitochondria in the electron transport function. In communication, recognition, and immunity cases in all cells, lipids also play important roles.

MS is a repetitive or progressive inflammatory demyelinating disease of the central nervous system. The attack of the immune system to the neural myelins at the time of the attack of the patient leads to disorders in the nerve conduction. The formation of plaques with demyelinating in the brain and sometimes in the spinal cord in MS causes pyramidal, sensory, cerebellar, rarely autonomic and extrapyramidal system disorders [16]. Zhornitsky et al. reported that 24-hydroxycholesterol and 27-hydroxycholesterol, which are the intermediate products of MS disease and lipid peroxidation, cause cell damage. These molecules play a role in the MS progression. It is reported that MS disease progresses as cell damage and neurotoxicity increase [17]. Lazar et al. determined that lipid peroxidation is effective in some neurodegenerative diseases such as Alzheimer's disease, MS and Huntington's disease [18]. There are other studies that prove that lipid peroxidation is higher in MS patients [19-23].

\section{Parkinson's disease}

The main symptoms of Parkinson's disease are the slowness and stiffness of walking and movements, difficulty in initiating movements and in fine works, dull face, muscle stiffness, hand and leg tremor while resting, deterioration of posture, balance, and reflexes, bending forward of the body [24].

The most characteristic feature of Parkinson's disease is the occurrence of degeneration and cell loss in a cell group called 'substantia nigra' which is bilaterally symmetrically located in the area called the brain stem. At least $60-70 \%$ of the cells have to be lost for the development of Parkinson's disease. In fact, the disease starts long before the symptoms emerge. Dopamine is a neurotransmitter produced in the area designated to be substantia nigra. With the damage to this region, dopamine deficiency and difficulty in initiating the movements and progressing them in a harmonious way occur. The greater the dopamine deficiency of the patients is, the greater the distresses about the movement are. However, there is no direct correlation between the excess tremor and the decrease in dopamine. Parkinson's disease is a slowly progressing disease. Studies have been conducted on the fact that in Parkinson's disease, lipid peroxidation increases specifically in the 'substantia nigra' region and causes the degenerative death of cells in this region [25-27]. 
Citation: Akman H, Bayrakl I, Kutluhan S (2018) Investigation of Correlation between Neurological Diseases and Breath Hexanal. J Bioanal Biomed 10: 56-59. doi:10.4172/1948-593X.1000205

In our study, no statistically significant correlation was observed between the levels of hexanal molecules in the breaths of the patients and the healthy control group, although there are studies on the presence of lipid peroxidation in Parkinson's patients.

\section{Conclusion}

As far as we know, neurological diseases have not been studied extensively with the methods of breath analysis. In this study we conducted, the relationship between hexanal molecules and neurological diseases as MS and Parkinson's was examined. Statistically significant differences were observed between the hexanal molecule in breath of MS patients and the control group. The high levels of hexanal molecule in MS patients may indicate a high level of lipid peroxidation in these diseases. No correlation was found between the hexanal levels in the breaths of Parkinson's patients and the healthy control group. MS attacks are currently diagnosed with MR. During the patient's waiting for MR; the attack status can damage the patient. Immediate results given diagnose techniques and studies for MS are a need in this area.

\section{Acknowledgments}

TD/GC-MS analyses were performed by the Scientific and Technological Application and Research Center of Mehmet Akif Ersoy University.

\section{References}

1. M Kangalgil, E Canbolat (2016) Role of cholesterol in the pathogenesis of some neurological diseases. Eur J Heal Sci 2: 56-63.

2. Coyle JT, Puttfarcken P (1993) Oxidative stress, glutamate, and neurodegenerative disorders. Science 262: 689-695.

3. Toshniwal PK, Zarling EJ (1992) Evidence for increased lipid peroxidation in multiple sclerosis, Neurochem. Res 17: 205-207.

4. Tisch U, Schlesinger I, lonescu R, Nassar M, Axelrod N, et al. (2013) Detection of Alzheimer's and Parkinson's disease from exhaled breath using nanomaterial-based sensors. Nanomedicine 8: 43-56.

5. Ionescu R, Broza Y, Shaltieli H, Sadeh D, Zilberman Y, et al. (2011) Detection of multiple sclerosis from exhaled breath using bilayers of polycyclic aromatic hydrocarbons and single-wall carbon nanotubes. ACS Chem. Neurosci 2: 687-693.

6. Paul R, Choudhury A, Borah A (2015) Cholesterol - A putative endogenous contributor towards Parkinson's disease. Neurochem. Int 90: 125-133.

7. Demirci S1, Kutluhan S, NaziroÄŸlu M, UÄŸuz AC, YÃ̄1/4rekli VA, et al. (2013) Effects of selenium and topiramate on cytosolic $\mathrm{Ca}(2+)$ influx and oxidative stress in neuronal PC12 cells. Neurochem Res 38: 90-97.

8. Higdon A, Diers AR, Oh JY, Landar A, Darley-Usmar VM (2012) Cell signalling by reactive lipid species: new concepts and molecular mechanisms. Biochem J 442: 453-464.

9. Stanley DE (1999) Tietz Textbook of Clinical Chemistry. JAMA J Am Med Assoc 282: 283-283.
10. Akkus I (1995) Free radicals and physiopathological effects. ( $1^{\text {st }}$ edn) Mymoza Publications.

11. Dillard CJ, Tappel AL (1989) Tappel, Lipid peroxidation products in biological tissues. Free Radic Biol Med 7: 193-196.

12. Orhan $H$ (2007) Analyses of representative biomarkers of exposure and effect by chromatographic, mass spectrometric, and nuclear magnetic resonance techniques: method development and application in life sciences. J Sep Sci 30: 149-174.

13. Esterbauer H, Schaur RJ, Zollner H (1991) Chemistry and biochemistry of 4-hydroxynonenal, malondialdehyde, and related aldehydes. Free Radic Biol Med 11: 81-128.

14. Pryor WA, Das B, Church DF (1991) The ozonation of unsaturated fatty acids: aldehydes and hydrogen peroxide as products and possible mediators of ozone toxicity. Chem Res Toxicol 4: 341-348.

15. Kinter M (1995) Analytical technologies for lipid oxidation products analysis, J Chromatogr B Biomed Appl 671: 223-236.

16. Tutkan H (2006) Autonomic Function Disorders in Multiple Sclerosis. Dr. Lütfi Kirdar Kartal Training and Research Hospital. Neurology Klin.

17. Zhornitsky S, McKay KA, Metz LM, Teunissen CE, Rangachari M (2016) Cholesterol and markers of cholesterol turnover in multiple sclerosis: Relationship with disease outcomes. Mult Scler Relat Disord 5: 53-65.

18. Kunos L, Bikov A, Lazar Z, Korosi BZ, Benedek P, et al. (2015) Evening and morning exhaled volatile compound patterns are different in obstructive sleep apnoea assessed with electronic nose. Sleep Breath 19: 247-253.

19. Wang P, Xie K, Wang C, Bi J (2014) Oxidative stress induced by lipid peroxidation is related with inflammation of demyelination and neurodegeneration in multiple sclerosis, Eur Neurol 72: 249-254

20. Van de Kraats C, Killestein J, Popescu V, Rijkers E, Vrenken H, et al. (2014) Oxysterols and cholesterol precursors correlate to magnetic resonance imaging measures of neurodegeneration in multiple sclerosis. Mult Scler J 20: 412-417.

21. Miller E, Mrowicka M, Saluk-Juszczak J, Ireneusz M (2011) The level of isoprostanes as a non-invasive marker for in vivo lipid peroxidation in secondary progressive multiple sclerosis, Neurochem Res 36: 1012-1016.

22. Gilgun-Sherki Y, Melamed E, Offen D (2004) The role of oxidative stress in the pathogenesis of multiple sclerosis: The need for effective antioxidant therapy. J Neurol 251: 261-268.

23. Besler HT, ComoÄŸlu S, OkÃßu Z (2002) Serum levels of antioxidant vitamins and lipid peroxidation in multiple sclerosis. Nutr Neurosci 5: 215-220.

24. Emre M (2006) 99 pages in Alzheimer's, Parkinson's. Turkey Is Bankasi.

25. Dexter DT, Carter CJ, Wells FR, Javoy-Agid F, Agid Y, et al. (1989) Basal Lipid Peroxidation in Substantia Nigra Is Increased in Parkinson's Disease. J Neurochem 52: 381-389.

26. Jenner $P$ (1998) Oxidative mechanisms in nigral cell death in Parkinson's disease. Mov Disord 1: 24-34.

27. Mylonas C, Kouretas D (1999) Lipid peroxidation and tissue damage. In Vivo 13: $295-309$. 